\title{
EVALUATION OF COLOUR IN WHITE AND YELLOW TRIFOLIATE YAM FLOURS IN RELATION TO HARVESTING PERIODS AND PRE-PROCESSING METHODS
}

\author{
Abiodun, O.A. ${ }^{*}$, Akinoso, R. ${ }^{2}$ and Dauda, A.O. ${ }^{1}$ \\ 1 Department of Home Economics and Food Science, University of llorin, Kwara \\ State, Nigeria. \\ 2Department of Food Technology, University of Ibadan, Oyo State, Nigeria. \\ *Corresponding E-mail Address: funmiabiodun2003@yahoo.com
}

\section{ABSTRACT}

Colour is one of the important sensory properties that determine the acceptability of food products. Therefore, this work determines the colour in white and yellow trifoliate yam flours in relation to harvesting periods and pre-processing methods. Freshly harvested trifoliate yam tubers were prepared into flour using four pretreatment (untreated, soaking at ambient temperature, soaking at $60{ }^{\circ} \mathrm{C}$ and parboiling at $98{ }^{\circ} \mathrm{C} \pm 2$ ) methods. The flour colour was analyzed and the whiteness index was determined. $L^{*}$ (brightness) value ranged from 68.90 in parboiled yellow trifoliate yam harvested at 8 months to 96.57 in the raw white trifoliate flour harvested at 9 months. Parboiled trifoliate yams from the two cultivars harvested at 11 months were darker in colour than other flour. Parboiled yellow trifoliate yam flours were significantly $(p>0.05)$ different from other samples in colour. The intensity of colour of the parboiled yellow trifoliate yam flour was more pronounced than others. However, the colour of the flour became deeper with prolonged harvesting periods and prominent in parboiled samples at 11 months.

Keywords: Colour, Harvesting periods, Pre-treatment, White trifoliate yam, Yellow trifoliate yam

\section{INTRODUCTION}

Yams are made up of carbohydrate and represents $20 \%$ of daily caloric intake of Nigerians living in the forest, Savannah region and South Eastern part of Nigeria (Madukwe, 1995). Yam is highly revered among the people but its cultivation is declining as a result of high incidence of field diseases, pest attack and high postharvest losses (Oluwasusi and Tijani, 2013). According to Ada-Okungbona 
(1998), there is the need to develop the marketing system through research so that the consumers can be assured of continuous supply of the tubers at all times and at reasonable prices. Trifoliate yam is among the unpopular yam species with high nutritional values. It has high protein $(9.6 \%)$ and mineral contents when compared to other yam species. Cultivation of this crop can improve food insecurity due to its high yielding property which makes it a special yam species. Cultivation of trifoliate yam is limited to some farmers due to the market value. Generally, white yam species are more acceptable worldwide and industrially due to ease of processing into other products. Research has shown that trifoliate yam had smaller starch granules which are more digestible than other yam species. Likewise, IITA (2008) have reported that yellow trifoliate yam is more pigmented than other yam species and concluded that the pigmentation are due to the presence of carotenoids, which confirms the high nutritional value reported for trifoliate yam. However, Abiodun et al. (2014a, b) have worked on the carotenoids contents of trifoliate yam tubers and flours but the colour of yellow trifoliate yam tuber has not been extensively studied. The colour of yellow trifoliate yam tuber varies from pale to deep yellow. Therefore, this paper aims at evaluating the colour in white and yellow trifoliate yam flours in relation to harvesting periods and pre-processing methods.

\section{MATERIALS AND METHODS}

The trifoliate yam setts of two cultivars (white and yellow) were collected from EsaOke farm settlements, Osun State, Nigeria.

\section{Samples Preparation}

Trifoliate yam setts weighing 850 - $900 \mathrm{~g}$ were planted in mounds with 10 per row and spacing of $1 \mathrm{~m} X 1 \mathrm{~m}$ on a plot of land. Thirty samples were planted per each cultivar. The planting was done on $20^{\text {th }}$ March, 2010 and sprouting of some of the yam setts occurred on $26^{\text {th }}$ of April, 2010. These trifoliate yam setts were marked and used for the study. After sprouting and vines establishment, the yams were staked. The plot of land was kept weed-free manually at a month interval after planting. There was no application of chemicals of any kind either as fertilizer, pest control or herbicides. The yam tubers were harvested in a month interval starting from November 26 th $2010-M a r c h 26^{\text {th }}$ 2011. The experiment was repeated in November 2011-March 2012 and November 2012-March 2013 (Abiodun and Akinoso, 2014). 


\section{Preparation of raw flour}

The freshly harvested yam tuber was washed, drained and peeled. The peeled tuber was sliced $\left(0.5 \mathrm{~mm}\right.$ thickness) and dried in the hot air oven at $60^{\circ} \mathrm{C}$ for $48 \mathrm{~h}$. The dried chips were milled into flour with hammer mill and sieved with $600 \mu \mathrm{m}$ sieve size. The flour samples were sealed in polythene bag (Abiodun and Akinoso, 2014).

\section{Preparation of soaked raw flour}

The freshly harvested yam tuber was washed, drained and peeled. The peeled tuber was sliced $\left(0.5 \mathrm{~mm}\right.$ thickness), soaked in water at ambient temperature $\left(29 \pm 2{ }^{\circ} \mathrm{C}\right)$ for $1 \mathrm{~h}$ and dried in the hot air oven at $60^{\circ} \mathrm{C}$ for $48 \mathrm{~h}$. The dried chips were milled into flour with hammer mill and sieved with $600 \mu \mathrm{m}$ sieve size. The flour samples were sealed in polythene bag (Abiodun et al., 2009)

\section{Preparation of soaked $\left(60^{\circ} \mathrm{C}\right)$ flour samples}

The freshly harvested yam tuber was washed, drained and peeled. The peeled tuber was sliced $\left(0.5 \mathrm{~mm}\right.$ thickness) and soaked in warm water $\left(60^{\circ} \mathrm{C}\right)$ for $10 \mathrm{~min}$. The sample was soaked in the water for $12 \mathrm{~h}$ at ambient temperature and dried in the oven $60^{\circ} \mathrm{C}$ for $48 \mathrm{~h}$. The dried chips were milled into flour with hammer mill and sieved with 600 $\mu \mathrm{m}$ sieve size (Ukpabi and Omodamiro, 2008).

\section{Preparation of parboiled samples}

The freshly harvested yam tuber was washed, peeled, sliced $(0.5 \mathrm{~mm}$ thickness) and parboiled for $10 \mathrm{~min}$ in water bath maintained at $100 \pm 2{ }^{\circ} \mathrm{C}$. The samples were dried in an oven set at $60^{\circ} \mathrm{C}$ for $48 \mathrm{hrs}$. The dried chips were milled into flour with hammer mill and sieved with 600 $\mu \mathrm{m}$ sieve size (Ekwu et al., 2005).

\section{Colour measurement}

The colour attributes (Hunter $L, a$, and $b$ values) of the yam flours and pastes (obtained with a Rapid Visco Analyser) were measured using a Minolta portable chroma-metre. The hunter lab colour coordinates system $L^{*} a^{*}$ and $b^{*}$ values were recorded and the brown index was calculated. Each sample was measured at four spots using standard $L^{*}=53.44, a^{*}=-24.94, b^{*}=12.94$ values. Whiteness index (WI) was calculated according to Hsu et al. (2003) and brown index (BI) by Babajide et al. (2006). The whiteness and brown indices were calculated using equation

$W I=100-\sqrt{(100-L)^{2}+a^{2}+b^{2}}$

$B I=100-L$ 
where: $L, a$, and $b$ were Hunter $L^{*}=$ Whiteness, $a^{*}=$ Redness and $b^{*}=$ yellowness values.

\section{RESULTS AND DISCUSSION}

\section{Effect of harvesting periods on the colour parameters of trifoliate yam flours}

Table 1 and 2 show the effect of harvesting periods and pre-treatment methods on the colour parameters of trifoliate yam flours. The $L^{*}$ value ranged from 68.90 in parboiled yellow trifoliate yam harvested at 8 months to 96.57 in the raw white trifoliate flour harvested at 9 months. Change in colour of the dried trifoliate yam chips were noticed with harvesting periods and pre-processing methods used (Plate 1). Milling the chips into flour provides a range of particle sizes. This distribution of particle sizes caused some of the flours to show a great deal of variability (Plate 2). The brightness value ( $\mathrm{L}^{*}$ value) diminished with harvesting periods and preprocessing methods. Soaking method improved the brightness of the flour while soaking at $60^{\circ} \mathrm{C}$ and pre-cooking methods reduced the whiteness index of the flour. The yellowness $\left(b^{*}\right)$ values were higher in the parboiled yellow trifoliate yam flours. The $b^{*}$ values of parboiled white trifoliate yam flours increased with harvesting periods and parboiling method. Parboiling of trifoliate yam tuber preserved the colour of the yam however, the intensity of the colour increased with period of harvesting. For both trifoliate yam cultivars, the yam chips and flours were lighter in colour at the early stage than the later stage of harvesting.

Whiteness indices were higher in the raw trifoliate yam flours than the pre-treated flours with higher values in white trifoliate yam flours when compared to yellow trifoliate yam flour at different harvesting periods. Whiteness index represents the overall whiteness of food products that may indicate the extent of discoloration during the drying process (Hsu et al., 2003). The parboiled yellow flours tend toward yellowness and redness than other flours and the flours became darker in colour with prolonged harvesting periods. The colour of raw and soaked yellow trifoliate yam flours faded during drying due to oxidation and bleaching of the carotenoids present in the yam. Potter (1986) reported that carotenoids are sensitive to oxidation, which resulted in both colour loss and destruction of vitamin A activity. Colours of the raw and pre-treated flours changed with harvesting periods and pretreatment methods. 
Table 1: Effect of harvesting periods and pre-treatment methods on the colour of yellow trifoliate yam flour

\begin{tabular}{|c|c|c|c|c|}
\hline \multirow[t]{2}{*}{ Treatment } & \multirow{2}{*}{$\begin{array}{l}\text { Harvesting } \\
\text { periods (months) }\end{array}$} & \multicolumn{3}{|c|}{ Colour Values } \\
\hline & & $\mathrm{L}^{*}$ & $a^{*}$ & $b^{*}$ \\
\hline \multirow[t]{5}{*}{ Untreated } & 7 & $91.12 \pm 0.16^{f}$ & $1.10 \pm 0.81 \mathrm{mn}$ & $10.21 \pm 0.30^{\mathrm{s}}$ \\
\hline & 8 & $91.37 \pm 0.21^{d}$ & $1.12 \pm 0.50^{\mathrm{lm}}$ & $10.33 \pm 0.10^{r}$ \\
\hline & 9 & $92.24 \pm 0.45^{c}$ & $1.13 \pm 0.23^{1 \mathrm{~m}}$ & $11.14 \pm 0.47 \mathrm{~m}$ \\
\hline & 10 & $90.20 \pm 0.11 j$ & $1.20 \pm 0.15^{k}$ & $11.17 \pm 0.22$ \\
\hline & 11 & $90.85 \pm 0.24^{\mathrm{h}}$ & $1.15 \pm 0.40^{\prime}$ & $12.08 \pm 0.16$ \\
\hline Soaking & 7 & $92.40 \pm 0.30^{\mathrm{b}}$ & $1.10 \pm 0.14 \mathrm{mn}$ & $10.58 \pm 0.43^{\circ}$ \\
\hline \multirow[t]{4}{*}{ (ambient) } & 8 & $92.70 \pm 1.01^{a}$ & $1.13 \pm 0.27 \mathrm{~lm}$ & $11.62 \pm 0.66^{k}$ \\
\hline & 9 & $91.06 \pm 0.72^{g}$ & $1.07 \pm 0.11^{\circ}$ & $10.87 \pm 0.62^{n}$ \\
\hline & 10 & $91.30 \pm 0.31 \mathrm{e}$ & $1.10 \pm 0.21 \mathrm{mn}$ & $10.44 \pm 0.14 q$ \\
\hline & 11 & $90.71 \pm 0.44$ & $1.30 \pm 0.67^{j}$ & $10.49 \pm 0.55^{p}$ \\
\hline Soaking & 7 & $86.67 \pm 0.41^{\circ}$ & $3.45 \pm 0.42^{f}$ & $23.56 \pm 0.27^{i}$ \\
\hline \multirow[t]{4}{*}{$\left(60^{\circ} \mathrm{C}\right)$} & 8 & $87.98 \pm 1.20 \mathrm{~m}$ & $2.59 \pm 0.73^{i}$ & $24.45 \pm 0.14^{f}$ \\
\hline & 9 & $89.06 \pm 0.33^{k}$ & $2.70 \pm 0.18^{\mathrm{h}}$ & $24.39 \pm 0.219$ \\
\hline & 10 & $87.30 \pm 0.21^{n}$ & $3.20 \pm 0.20 \mathrm{~g}$ & $24.32 \pm 0.70^{\mathrm{h}}$ \\
\hline & 11 & $88.71 \pm 0.50^{\prime}$ & $3.50 \pm 0.11^{e}$ & $24.43 \pm 0.29^{f}$ \\
\hline \multirow[t]{5}{*}{ Parboiling } & 7 & $70.52 \pm 0.11 r$ & $13.69 \pm 0.62^{d}$ & $40.96 \pm 0.36 \mathrm{e}$ \\
\hline & 8 & $69.30 \pm 0.42^{\mathrm{s}}$ & $13.72 \pm 0.35^{d}$ & $42.62 \pm 0.10^{c}$ \\
\hline & 9 & $71.19 \pm 0.34 \mathrm{q}$ & $14.09 \pm 0.22^{c}$ & $42.18 \pm 0.19 d$ \\
\hline & 10 & $68.90 \pm 0.45^{t}$ & $14.83 \pm 0.19^{a}$ & $43.99 \pm 0.23^{b}$ \\
\hline & 11 & $72.10 \pm 0.40 p$ & $14.78 \pm 0.20^{b}$ & $44.91 \pm 0.48^{a}$ \\
\hline
\end{tabular}

Values with the same superscript down the column were not significantly different $(p<$ 0.05) 
Table 2: Effect of harvesting periods and pre-treatment methods on the colour of white trifoliate yam flour

\begin{tabular}{|c|c|c|c|c|}
\hline \multirow[t]{2}{*}{ Cultivar } & \multirow{2}{*}{$\begin{array}{l}\text { Harvesting } \\
\text { periods } \\
\text { (months) }\end{array}$} & \multicolumn{3}{|c|}{ Colour Values } \\
\hline & & $L^{*}$ & $a^{*}$ & $b^{*}$ \\
\hline \multirow[t]{5}{*}{ Untreated } & 7 & $96.37 \pm 0.16^{b}$ & $0.21 \pm 0.81^{n}$ & $6.22 \pm 0.30^{9}$ \\
\hline & 8 & $96.60 \pm 0.21^{a}$ & $0.29 \pm 0.50^{\prime}$ & $6.54 \pm 0.10^{p}$ \\
\hline & 9 & $96.57 \pm 0.45^{a}$ & $0.35 \pm 0.23$ & $7.79 \pm 0.47^{\mathrm{k}}$ \\
\hline & 10 & $95.87 \pm 0.11^{c}$ & $0.37 \pm 0.15^{i}$ & $8.65 \pm 0.22^{j}$ \\
\hline & 11 & $95.66 \pm 0.24 \mathrm{e}$ & $0.48 \pm 0.40 \mathrm{~g}$ & $9.18 \pm 0.16^{f}$ \\
\hline Soaking & 7 & $95.91 \pm 0.30^{c}$ & $0.24 \pm 0.14 \mathrm{~m}$ & $5.24 \pm 0.43^{s}$ \\
\hline \multirow{4}{*}{ (ambient) } & 8 & $95.87 \pm 1.01^{c}$ & $0.32 \pm 0.27^{k}$ & $5.31 \pm 0.66^{r}$ \\
\hline & 9 & $95.64 \pm 0.72^{\mathrm{e}}$ & $0.39 \pm 0.11 i$ & $6.72 \pm 0.62^{\circ}$ \\
\hline & 10 & $94.88 \pm 0.31^{f}$ & $0.46 \pm 0.21 \mathrm{~g}$ & $6.70 \pm 0.14^{\circ}$ \\
\hline & 11 & $93.70 \pm 0.44^{\mathrm{h}}$ & $0.46 \pm 0.67 \mathrm{~g}$ & $7.30 \pm 0.55$ \\
\hline Soaking & 7 & $95.75 \pm 0.41^{d}$ & $0.32 \pm 0.42^{k}$ & $7.13 \pm 0.27 \mathrm{~m}$ \\
\hline \multirow[t]{4}{*}{$\left(60^{\circ} \mathrm{C}\right)$} & 8 & $94.40 \pm 1.20 \mathrm{~g}$ & $0.37 \pm 0.73^{i}$ & $7.30 \pm 0.14$ \\
\hline & 9 & $93.27 \pm 0.33^{i}$ & $0.43 \pm 0.18^{h}$ & $8.77 \pm 0.21^{i}$ \\
\hline & 10 & $93.17 \pm 0.21 j$ & $0.46 \pm 0.20^{g}$ & $8.84 \pm 0.70^{\mathrm{h}}$ \\
\hline & 11 & $92.10 \pm 0.50^{k}$ & $0.50 \pm 0.11^{f}$ & $8.99 \pm 0.299$ \\
\hline \multirow[t]{5}{*}{ Parboiling } & 7 & $88.57 \pm 0.11^{\prime}$ & $1.82 \pm 0.62^{\mathrm{e}}$ & $16.90 \pm 0.36^{d}$ \\
\hline & 8 & $86.73 \pm 0.42^{m}$ & $2.03 \pm 0.35^{d}$ & $16.60 \pm 0.10^{e}$ \\
\hline & 9 & $86.51 \pm 0.34^{n}$ & $3.56 \pm 0.22^{b}$ & $18.47 \pm 0.19 c$ \\
\hline & 10 & $81.55 \pm 0.45^{\circ}$ & $3.08 \pm 0.19^{c}$ & $19.68 \pm 0.23^{b}$ \\
\hline & 11 & $78.10 \pm 0.40^{p}$ & $4.13 \pm 0.20^{\mathrm{a}}$ & $20.43 \pm 0.48^{a}$ \\
\hline
\end{tabular}

Values with the same superscript down the column were not significant different $(p<0.05)$

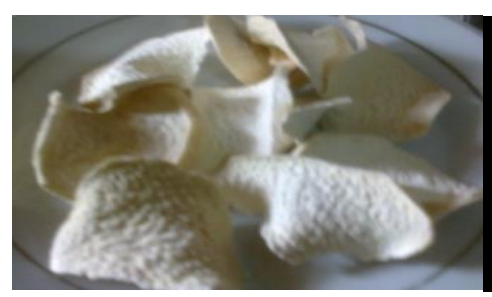

A

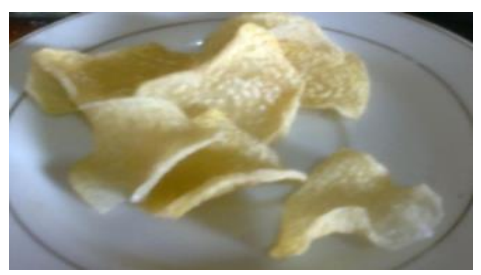

C

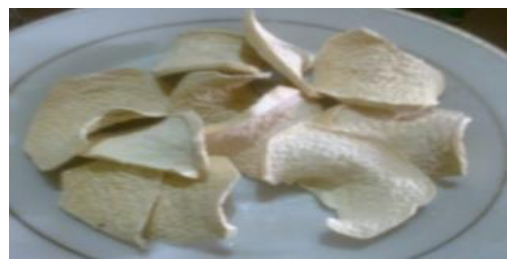

B

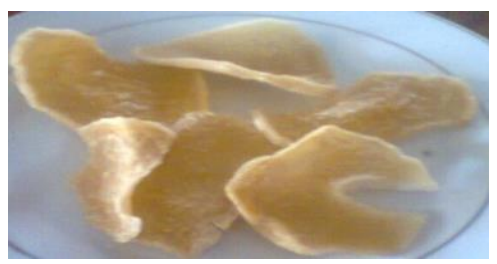

D 


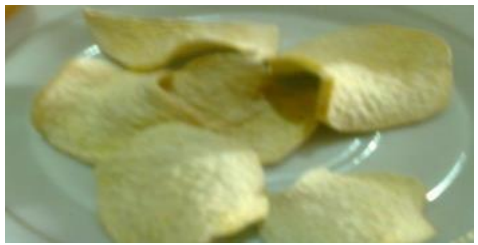

E

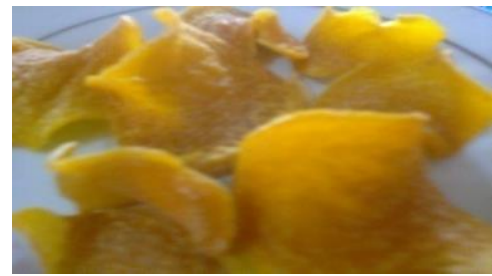

G

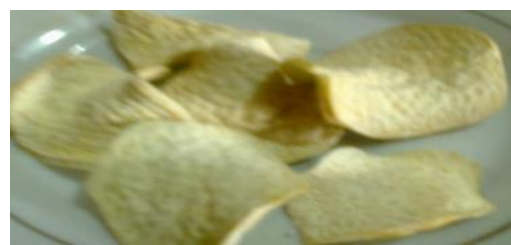

F

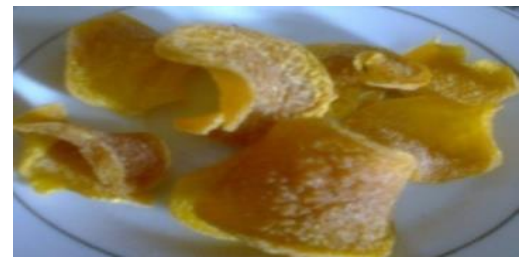

$\mathrm{H}$

Plate 1: Untreated and parboiled trifoliate yam chips

A-Raw white trifoliate yam chips at 9 months and B 11months, C-Parboiled white trifoliate yam chips at 9 months and $D$ at 11 months, E-Raw yellow trifoliate yam chips at 9 months and $F$ at 11 months, G-Parboiled yellow trifoliate yam at 9 months and 11 months.

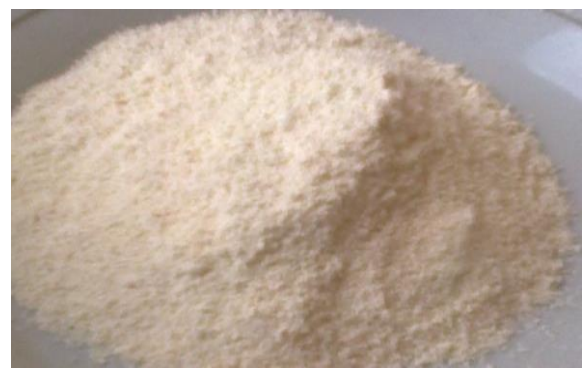

A

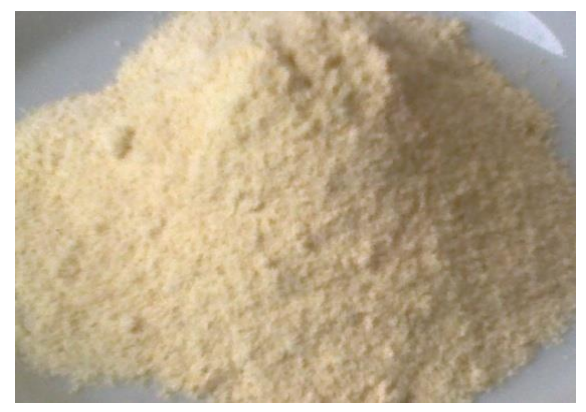

C

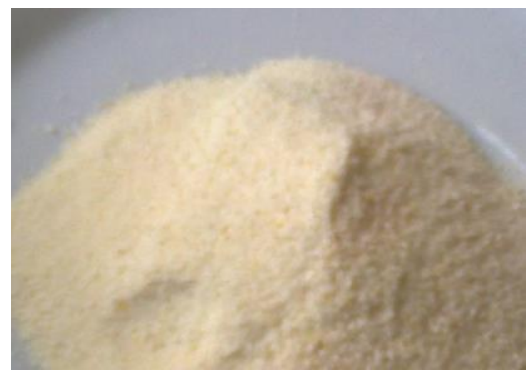

B

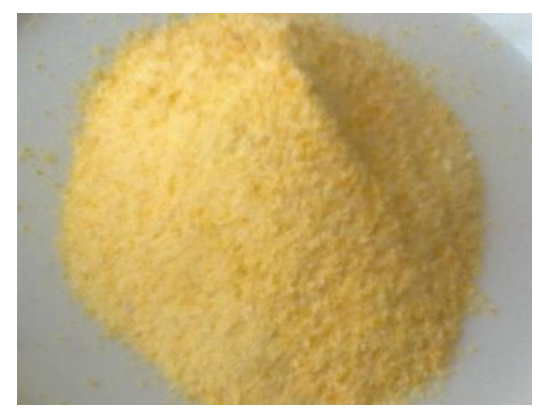

D 
Plate 2: Untreated and parboiled trifoliate yam flour. A- Raw white and B -parboiled white trifoliate yam tubers, C-Raw yellow and D-parboiled yellow trifoliate yam flour

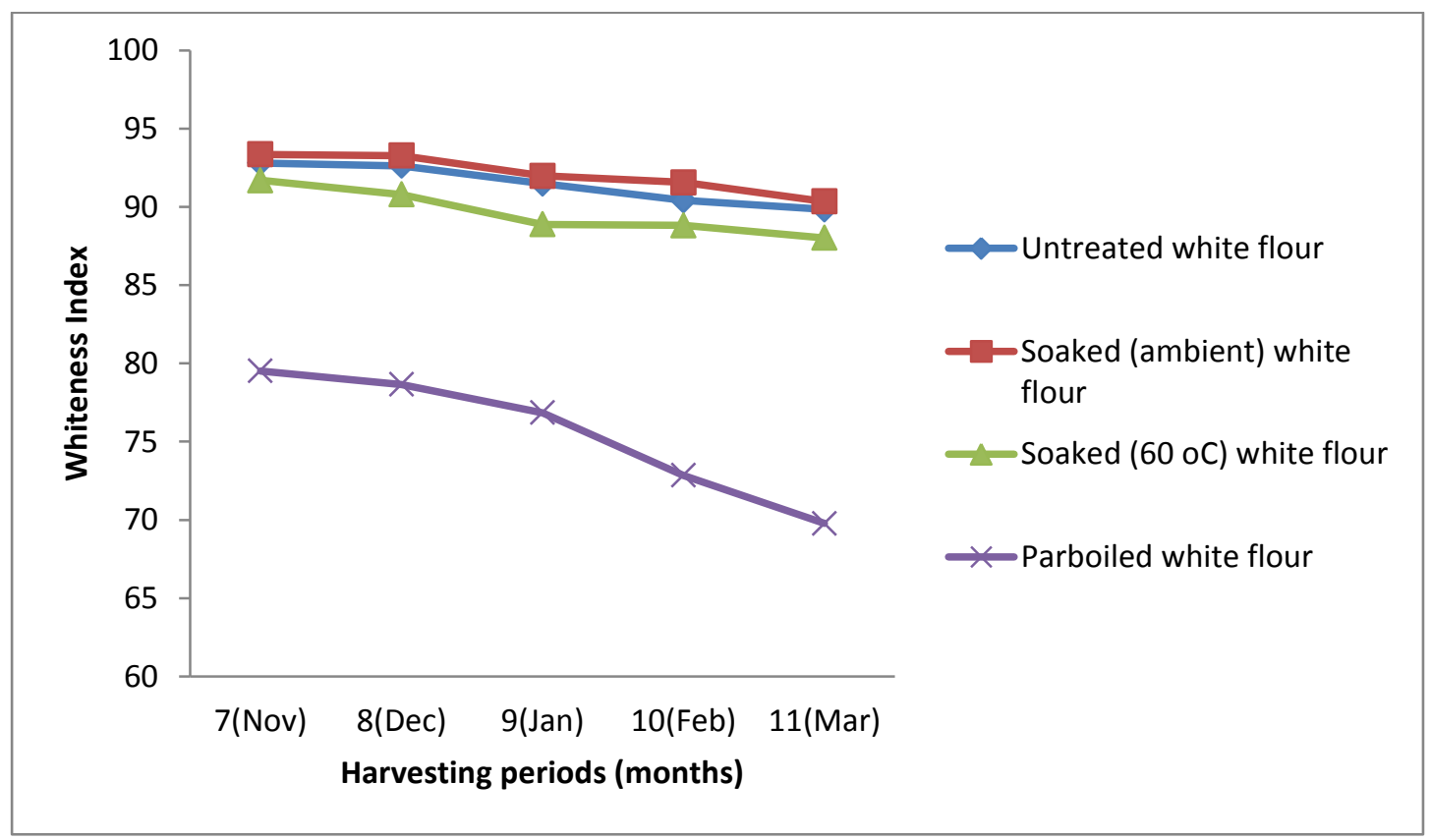

Fig. 1: Effect of pre-treatment and harvesting periods on the whiteness indices of white trifoliate yam flour 


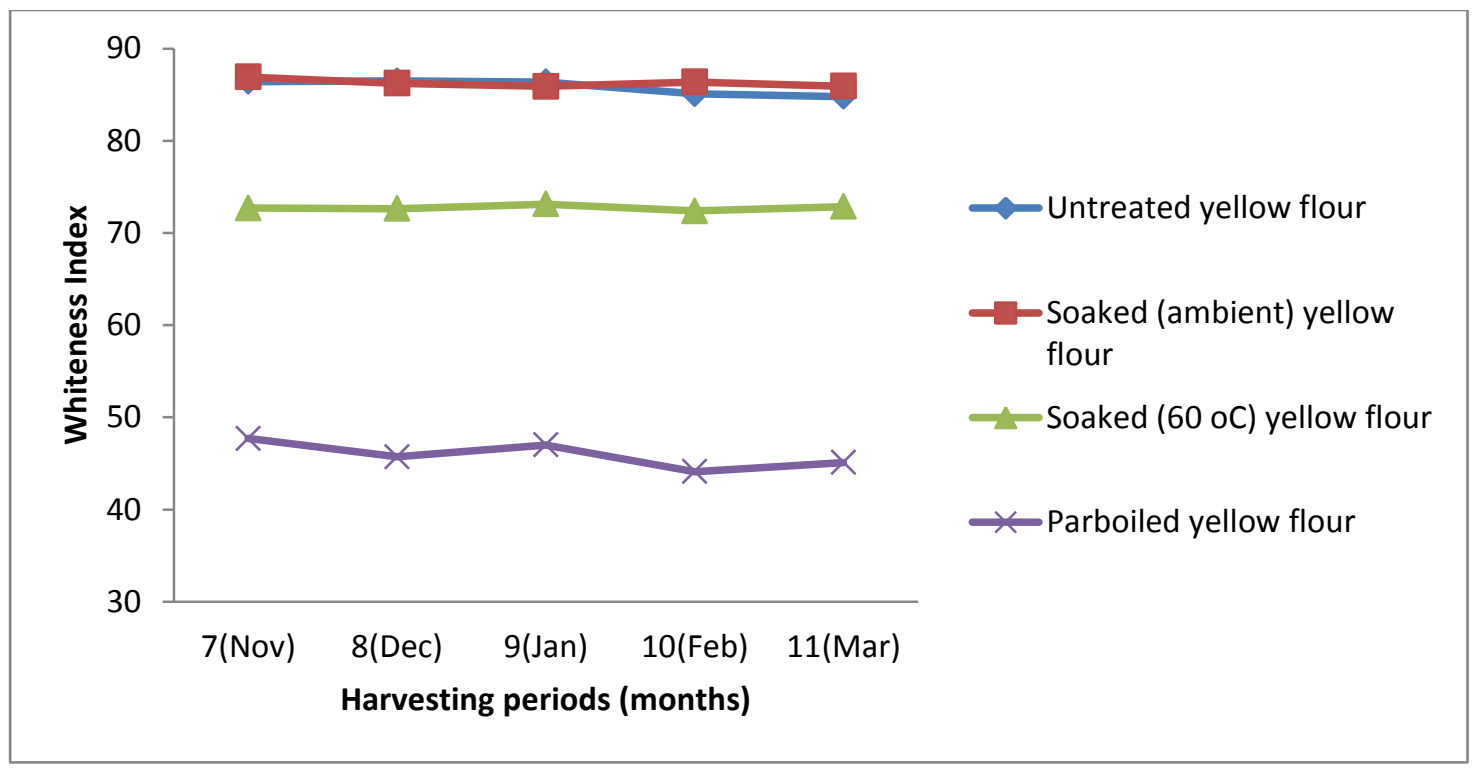

Fig. 2: Effect of pre-treatment and harvesting periods on the whiteness indices of yellow trifoliate yam flour

\section{CONCLUSIONS}

Colour of white and yellow trifoliate yam flours as affected by harvesting periods and pre-processing methods were evaluated in this work. Colour of trifoliate yam flours harvested at 11 months were dark than those at earlier months. Whiteness indices decreased in parboiled flour samples and this was prominent in the parboiled white trifoliate yam flour. Bright colour trifoliate yam flour could be obtained at early harvesting periods (7 to 9 months) using different pre-processing methods based on the usefulness of the flour.

\section{REFERENCES}

Abiodun O.A and Akinoso, R. (2014). "Effect of delayed harvesting and pretreatment methods on the anti-nutritional contents of trifoliate yam flour". Food Chemistry. 146: 515-520

Abiodun O.A., Akinoso, R. and Akinwande, B.A. (2014a). "Carotenoid and volatile compounds in yellow trifoliate yam tuber". 17th IUFoST World Congress of 
Food Science and Technology and EXPO held at Monstreal, Canada, August 17-21st 2014

Abiodun, O.A., Adegbite, J.A. and Oladipo, T.S. (2009). "Effect of soaking time on the pasting properties of two cultivars of trifoliate yam (Dioscorea dumetorum)". Pakistan Journal of Nutrition. 8 (10): 1537-1539.

Abiodun, O.A., Akinoso, R. and Olosunde, O.O. (2014b). "Effect of harvesting periods and pre-treatment methods on the total carotenoid contents and colour of trifoliate yam flour". Third Applied Research Conference in Africa held in Accra, Ghana. 7-9th August, 2014

Ada_Okungbowa, C.I (1998). "The marketing structure, conduct and performance for yam in Ondo State, Nigeria". Agrosearch. 4 (1\&2): 12-20

Babajide, J. M., Oyewole, O. B., Henshaw, F. O., Babajide, S. O. and Olasantan, F. O. (2006). "Effect of local preservatives on quality of traditional dry yam slices 'Gbodo' and its products”. World Journal of Agricultural Sciences. 2(3): 267-273

Ekwu, F. C., Ozo, N. O. and Ikegwu, O. J. (2005). "Quality of fufu flour from white yam varieties (Dioscorea spp)". Nigerian Food Journal. 23: 107-113.

Hsu, C. L, Chen, W., Weng, Y. M. and Tseng, C. Y. (2003). "Chemical composition, physical properties, and antioxidant activities of yam flours as affected by different drying methods". Food Chemistry. 83(1): 85-92.

IITA (2008). "Yam carotenoids and health". The Bulletin No 1922.

Madukwe, M.C. (1995). "Obstacles to the adoption of yam minisett technology by small scale farmers of South-Eastern Nigeria". Agrosearch. 1(1): 1-6

Oluwasusi, J.O. and Tijani S.A. (2013). "Farmers Adaptations Strategies to effect of climate variation in yam production; A case study in Ekiti State, Nigeria". Agrosearch. 13(2): 20-31

Potter, N. N. (1986). "Food Science". Van Nostrand Reinhold Press, Ithaca, New York. Pp 113-117.

Ukpabi, U. J. and Omodamiro, R. M. (2008). "Assessment of hybrid white yam (Dioscorea rotundata) genotypes for the preparation of amala". Nigerian Food Journal. 26(1): 111-118 